\title{
The significance of the gut microbiome in children with functional constipation
}

\author{
Monika Kwiatkowska ${ }^{A-F}$, Aneta Krogulska ${ }^{A-F}$ \\ Department of Pediatrics, Allergology and Gastroenterology, Ludwik Rydygier Collegium Medicum in Bydgoszcz, Nicolaus Copernicus University in Toruń, Poland \\ A - research concept and design; B - collection and/or assembly of data; C - data analysis and interpretation; \\ $D$ - writing the article; $E$ - critical revision of the article; $F$ - final approval of the article
}

Address for correspondence

Monika Kwiatkowska

E-mail:monikasobecka5@gmail.com

Funding sources

None declared

Conflict of interest

None declared

Received on July 28,2020

Reviewed on October 12, 2020

Accepted on December 6, 2020

Published online on April 28, 2021

\begin{abstract}
Constipation is a widespread problem in pediatric practice, affecting almost $30 \%$ of pediatric population. As much as 90-95\% of constipation cases have a functional basis, and although the pathogenesis of functional constipation remains unclear, its etiology is considered to be multifactorial. Its growing prevalence has been attributed to the occurrence of disorders in the homeostasis of gastrointestinal microbiota. In humans, the best known microbiome is that of the intestines, which has been the subject of a number of studies based on recognition of the 165 rRNA gene sequence. Microbiota are believed to influence the pathogenesis of functional constipation by affecting peristalsis, relationship with diet, and physical activity. The paper evaluates the role of intestinal microbiota in functional constipation and describes its contribution to the onset of disease. Determining the importance of the microbiome in the pathogenesis of functional constipation creates hope for the development of new prevention and treatment methods.
\end{abstract}

Key words: microbiota, 165 rRNA, peristalsis, childhood

Cite as

Kwiatkowska M, Krogulska A. The significance of the gut

microbiome in children with functional constipation.

Adv Clin Exp Med. 2021;30(4):471-480.

doi:10.17219/acem/131215

DOI

10.17219/acem/131215

\section{Copyright}

Copyright by Author(s)

This is an article distributed under the terms of the

Creative Commons Attribution 3.0 Unported (CC BY 3.0)

(https://creativecommons.org/licenses/by/3.0/) 


\section{Introduction}

Constipation is a troublesome condition characterized by the production of hard, compact stool which requires great effort to pass. Consequently, stool is passed less frequently than would be typical for a given age. The norms of defecation frequency depending on age are presented in Table $1 .^{1}$ Constipation is one of the most common childhood complaints, being reported by up to $29.6 \%$ of the population of pediatric population. ${ }^{2-4}$ It is slightly more common in boys than in girls. ${ }^{5}$ The condition accounts for $3-5 \%$ of visits to pediatricians and $10-25 \%$ of visits to pediatric gastroenterologists. ${ }^{3,6}$ In addition to its widespread prevalence, constipation is also becoming more common; this rise has been attributed to a range of causes, such as poor diet, reduced physical activity, rapidly progressing socio-cultural changes, increasing stress levels, and inappropriate parental attitude. ${ }^{7,8}$ In as many as a quarter of children, the problem of constipation persists into adulthood. ${ }^{9}$ In addition, it is a clinical problem that generates high costs for healthcare: the number of children hospitalized due to constipation in the USA increased by $112 \%$ in the period 1997-2009, and the costs associated with hospitalization increased by $221.5 \%{ }^{7}$ The importance of constipation is demonstrated by its significant impact on the quality of life of both children and their families. ${ }^{3,7}$

Table 1. Normal frequency of bowel movements in infants and children'

\begin{tabular}{|c|c|c|}
\hline Age & $\begin{array}{c}\text { Mean number of bowel } \\
\text { movements per week }\end{array}$ & $\begin{array}{c}\text { Mean number of bowel } \\
\text { movements per day }\end{array}$ \\
\hline $\begin{array}{c}0-3 \text { months } \\
\text { (breastfed) }\end{array}$ & $5-40$ & 2.9 \\
\hline $\begin{array}{c}0-3 \text { months } \\
\text { (formula-fed) }\end{array}$ & $5-28$ & 2.0 \\
\hline 6-12 months & $5-28$ & 1.8 \\
\hline $1-3$ years & $4-21$ & 1.4 \\
\hline Over 3 years & $3-14$ & 1.0 \\
\hline
\end{tabular}

Constipation can cause a number of symptoms, such as abdominal pain, bloating, painful bowel movements, lack of appetite, fecal staining of underwear, vomiting, and even intestinal obstruction and perforation. ${ }^{3,8}$ In addition, children with constipation are more likely to suffer from urinary tract infections and bedwetting, ${ }^{10}$ and this cohort demonstrates an increased risk of various emotional disorders, such as anxiety and irritability. ${ }^{8} \mathrm{When}$ left untreated, or inadequately treated, long-term constipation can adversely affect child's development.

It is believed that $5 \%$ of cases of constipation may be organic in origin, while the other $95 \%$ are functional. Prevalence rates for functional constipation in children aged $0-18$ years range from $0.5 \%$ to $32.2 \%{ }^{11}$ The prevalence varies according to age groups, with the highest
Table 2. Differential diagnosis of constipation according to age in children ${ }^{12}$

\begin{tabular}{|l|c|c|}
\hline \multicolumn{1}{|c|}{ Cause of constipation } & Infants & $\begin{array}{c}\text { Children older } \\
\text { than 1 year }\end{array}$ \\
\hline Functional constipation & $\begin{array}{c}\text { rare (prevalence } \\
\text { 3-12.1\%) }\end{array}$ & $\begin{array}{c}\text { more than 95\% of cases } \\
\text { (prevalence 0.5-32.2\%) }\end{array}$ \\
\hline $\begin{array}{l}\text { Hirschsprung's disease } \\
\text { Congenital anorectal } \\
\text { malformations }\end{array}$ & yes & yes \\
\hline $\begin{array}{l}\text { Neurological disorders } \\
\text { Encephalopathy }\end{array}$ & yes \\
\hline $\begin{array}{l}\text { Spinal cord abnormalities: } \\
\text { myelomeningocele, spina } \\
\text { bifida, tethered cord }\end{array}$ & yes \\
\hline $\begin{array}{l}\text { Cystic fibrosis } \\
\text { Metabolic causes: } \\
\text { hypothyroidism, hyper- } \\
\text { calcemia, hypokalemia, } \\
\text { diabetes insipidus }\end{array}$ & yes & rarely \\
\hline Heavy metal poisoning & rarely \\
\hline $\begin{array}{l}\text { Medication side effects } \\
\text { Gluten enteropathy }\end{array}$ & yes & rarely \\
\hline Spinal cord trauma & no & yes \\
\hline $\begin{array}{l}\text { Neurofibromatosis } \\
\text { Developmental delay }\end{array}$ & rarely & yes \\
\hline rexual abuse & yes & yes \\
\hline
\end{tabular}

prevalence reported in toddlers. ${ }^{11}$ The differential diagnosis of constipation depending on age is presented in Table $2 .{ }^{12}$ The bases for recognizing functional constipation according to the Rome IV criteria are presented in Table $3 .{ }^{13,14}$

\section{Etiology of functional constipation}

Although the etiology of functional constipation is believed to be multifactorial, it remains poorly understood. ${ }^{7,15-17}$ The basic causative factor is believed to be conscious stopping of defecation due to pain or fear, thus resulting in a "vicious circle". ${ }^{15}$ Such withholding of stool is believed to be the cause of constipation in $50 \%$ of younger children. ${ }^{7}$ The prolonged stasis and accumulation of fecal mass leads to an enlargement of the rectum and a decrease in anal muscle contraction efficiency, resulting in pelvic floor muscle fatigue, weakness of anal sphincter function and fecal incontinence. ${ }^{7,16}$ Almost $30 \%$ of children with functional constipation soil their underwear. ${ }^{17}$

Functional constipation is typically categorized into normal transit constipation (NTC), slow transit constipation (STC), and defecatory or rectal evacuation disorders. Defecatory or rectal evacuation disorders are caused by pelvic floor dyssynergia (PFD) as well as a reduction in intraabdominal pressure, rectal sensory perception and rectal contraction. ${ }^{18}$ 
Table 3. Rome IV criteria for functional constipation ${ }^{13,14}$

\begin{tabular}{|c|c|c|}
\hline Criteria & Children $<4$ years * & Children $>4$ years $* *$ \\
\hline \multirow{8}{*}{$\begin{array}{l}\text { Rome IV } \\
\text { criteria }\end{array}$} & - 2 or fewer defecations per week & - 2 or fewer defecations in the toilet per week \\
\hline & - history of excessive stool retention & - at least 1 episode of fecal incontinence per week \\
\hline & - history of painful or hard bowel movements & - history of retentive posturing or excessive volitional stool retention \\
\hline & - history of large-diameter stools & - history of painful or hard bowel movements \\
\hline & - presence of a large fecal mass in the rectum & - presence of a large fecal mass in the rectum \\
\hline & $\begin{array}{l}\text { In toilet-trained children, the following additional criteria may be } \\
\text { used: }\end{array}$ & - history of large-diameter stools that can obstruct the toilet \\
\hline & $\begin{array}{l}\text { - at least } 1 \text { episode/week of incontinence after the acquisition } \\
\text { of toileting skills }\end{array}$ & \\
\hline & - history of large-diameter stools that may obstruct the toilet & \\
\hline
\end{tabular}

* Must fulfill $\geq 2$ criteria at least once per week for a minimum of 1 month with insufficient criteria for a diagnosis of irritable bowel syndrome.

** Must fulfill $\geq 2$ criteria at least once per week for a minimum of 1 month with insufficient criteria for a diagnosis of irritable bowel syndrome. After appropriate evaluation, the symptoms cannot be fully explained by another medical condition.

Rao et al. showed that dyssynergic defecation was detected in $27-59 \%$ of patients, slow colonic transit in 3-47\%, and an overlap of dyssynergic defecation and slow colonic transit or constipation-predominant irritable bowel syndrome (IBS-C) was commonly present. ${ }^{19}$ Dyssynergic defecation is common and affects up to $1 / 2$ of patients with chronic constipation. ${ }^{19}$ The PFD prevalence varies between $11 \%$ and $74 \%$; it is typically present in about $50 \%$ of patients. The exact prevalence of PFD in children is unknown. According to Whitehead et al., PFD is found in 25-50\% of both children and adults. ${ }^{20}$ Another study showed slow transit constipation in $60 \%$ of the children with constipation, and among them, $13 \%$ had pelvic floor dysfunction. ${ }^{21}$ Zar-Kessler at al. completed a retrospective chart review over 15 months of patients aged 5-18 years with chronic constipation. They showed that $<50 \%$ of all studied patients met criteria for dyssynergic defecation

In addition, it has been found that children with motility disorders tend to display normal or slow bowel motor function. In addition, peristalsis may be slowed throughout the entire large intestine, resulting in inefficient movement of fecal masses and stool retention. Such problems, occurring as a result of slow passage of stools though the intestine, has been reported in $25 \%$ of older children by Rajindrajith et al. ${ }^{7}$ and in $13-25 \%$ of children by Nurko et al. ${ }^{23}$ A relationship has also been noted between motility disorders and intestinal microbiota. In contrast, defecatory and rectal evacuation disorders do not appear to be related to gut microbiota. ${ }^{18}$

Constipation can also occur due to abnormalities of the anorectum region which impede excretion of fecal masses, such as spastic pelvic floor spasm. ${ }^{17}$ In a study of 1400 adult patients with functional constipation, 65\% demonstrated constipation with normal intestinal passage time and 5\% with a longer time, while $30 \%$ had problems with fecal excretion from the end of the bowel. ${ }^{24}$

Constipation may also be caused by low fiber intake ${ }^{25}$ and lack of physical activity. ${ }^{26}$ In addition, obesity, closely related to physical activity and diet, is commonly associated with a higher risk of constipation, ${ }^{27}$ although no such relationship has been confirmed. ${ }^{28}$ Other lifestyle factors that increase the risk of constipation include poor socioeconomic conditions and low maternal education. ${ }^{4}$ Stress has also been found to be associated with constipation in children, ${ }^{29}$ which can lead to permanent changes in gastrointestinal motility, visceral sensitivity and hypothalamic-pituitary-adrenal dysfunction. ${ }^{7,26}$ In addition, constipation has been found to be more common in children who receive less attention from parents, and who may get insufficient sleep. ${ }^{29}$

In addition to environmental factors, genetic factors may also be important in the development of constipation, since it has been shown that a positive family history has prognostic value ${ }^{30}$; however, no mutations in genes potentially related to functional constipation have been identified. ${ }^{31}$

One group of factors that has demonstrated increasing significance in constipation is that of disorders in the homeostasis of the intestinal microbiota. ${ }^{2,15}$

\section{Diversity of the intestinal microbiota at different levels of the digestive tract}

The intestines are the most widely colonized organ in the human body, with colonization mainly with bacteria of the Firmicutes, Bacteroidetes, Proteobacteria, and Actinobacteria, but also by fungi, viruses and archaea. ${ }^{32}$ The total mass of bacteria in the intestine is believed to range from $1.5 \mathrm{~kg}$ to $2 \mathrm{~kg}$. Due to the variation in their conditions and function, each section of the digestive system is characterized by a unique microbial community. The oral cavity is typically inhabited by 108 CFU (colony forming units) per gram of fecal content, with the genera 
Actinobacteria, Saccharibacteria, Proteobacteria (class beta), Fusobacteria, Firmicutes (mainly Negativicutes and Bacilli), and Bacteroides (Flavobacteria, Prevotella) predominating. The esophagus and upper gastrointestinal tract are characterized by a relatively fast transport of gastrointestinal content, which is not conducive to the development of microorganisms; similarly, the stomach and the initial section of the small intestine have very low $\mathrm{pH}$ and high passage speed, and hence typically demonstrate 101-103 bacteria/gram of fecal matter, with acid-resistant Lactobacilli predominating. In comparison, a more diverse microbiota is found in the distal section of the small intestine, where 105 bacteria/gram of fecal matter is typically found. The most numerous, and most active, microorganism complex can be found in the large intestine, with 1011-1012 microbes/gram of fecal content; this higher number is most likely due to the slower passage of feces. ${ }^{32}$ This region has been shown to be dominated by anaerobic bacteria. ${ }^{33}$

\section{The significance of the microbiota of the digestive tract for health}

The microbiota creates a unique ecosystem that performs many functions important for maintaining homeostasis, i.e., it is responsible for the energy balance of the body, ${ }^{34}$ and is involved in digestion, fermentation of nutrients and the storage of energy obtained from food by transformation to short-chain fatty acids (SCFAs). ${ }^{34}$ It is also responsible for the production of polyamines and vitamins $B$ and $\mathrm{K}$, as well as for mineral management. ${ }^{34}$ The microbiota also plays an important role in the proper functioning of the immune system. ${ }^{35}$ By releasing neurotransmitters and neuromodulators, such as dopamine, noradrenaline, acetylcholine, gamma aminobutyric acid, and serotonin, it also affects the function of the brain-gut axis. ${ }^{36}$ It has been demonstrated that direct contact of intestinal epithelial cells with the probiotic Lactobacillus acidophilus induces the expression of opioid and cannabinoid receptors in the intestine and is involved in the modulation of visceral pain perception. ${ }^{37}$

Although previous research has examined the significance of microbiota in a range of specific diseases, including allergic diseases, ${ }^{38}$ mental and neurodevelopmental disorders, ${ }^{39,40}$ diabetes, obesity, hypertension, cardiovascular disorders, ${ }^{41}$ coeliac disease, rheumatoid arthritis, inflammatory bowel disease (IBD), and colorectal cancer, ${ }^{8,35}$ the largest number of studies concerns functional disorders of the gastrointestinal tract. ${ }^{8}$ It is also important to note that although the microbiomes of various body compartments have been studied, most previous research has focused on the digestive tract. ${ }^{8}$

It is possible that the microbiota may play a direct or indirect role in the pathogenesis of functional constipation by influencing peristalsis, or by a relationship with diet and physical activity.

\section{The pathomechanisms behind the relationship between intestinal microbiota, peristaltic disorders and constipation}

Changes in the composition of the microbiota play an important role in the pathogenesis of many gastrointestinal functional disorders, including constipation. It has been observed that the composition of the gastrointestinal microbiota of individuals with constipation differs considerably from those without. ${ }^{6,15,39,40}$ Constipation is a disorder resulting from changes in the peristalsis of the digestive tract. The function of the intestine is maintained by a number of factors that play significant roles, including the nervous system, the immune system, bile acid metabolism, and the microbiota of the digestive tract. The cause-effect relationship between alterations in gut microbiota and gut dysmotility remains unclear. Some changes in the composition of the gut microbiota may be secondary to slower gastrointestinal transit.

In addition, the microbiota can influence intestinal peristalsis by various mechanisms described below.

\section{Changes in $\mathrm{pH}$ in the intestine}

Disruptions in the normal intestinal microbiota can result in changes in the fermentation of dietary fiber to SCFA, preventing the effective control of $\mathrm{pH}$ in the intestine and thus disrupting its peristalsis. In addition, abnormal $\mathrm{pH}$ prevents the development of certain components of the microbiota, particularly Lactobacillus and Bifidobacterium. Therefore, the composition of the microbiota both influences, and is influenced by, constipation. ${ }^{8,16}$

\section{Regulation of butyric acid concentration}

The proper composition of the microbiota maintains the concentration of butyric acid in the colon at an optimal level, maintaining the correct rhythm of bowel movements. The correct concentration of butyrate facilitates contractions of the smooth muscle in the colon, thus supporting intestinal motility and preventing constipation. However, at excessive concentrations, it inhibits muscle contraction and slows peristalsis. In addition, excessive concentrations of butyrate may favor the development of constipation by inhibiting mucin secretion from intestinal goblet cells, and decreasing stool volume by disturbing water and electrolyte absorption. This explains the occurrence of smaller numbers of Prevotella species (including P. veroralis, $P$. corporis and $P$. ruminicola), which do not produce butyric acid, in patients with constipation, and the greater number of butyric acid-producing Coprococcus, Roseburia and Faecalibacterium. Interestingly, while the presence of bacteria that produce butyrate in the intestinal mucosa 
(e.g., Faecalibacterium) is associated with a higher likelihood of constipation, the presence of those that produce butyric acid in the feces (e.g., Faecalibacterium, Roseburia and Coprococcus) actually increase the rate of peristalsis in the colon. ${ }^{39}$

\section{Production of methane in the intestinal lumen}

Disturbances in the composition of the microbiota influences the production of methane in the intestinal lumen, causing intestinal distension, reduction of smooth muscle contractility and a slowing of peristalsis. ${ }^{42}$

\section{Modulation of gene expression}

Experimental studies in mice have shown that microbes can modulate the expression of genes involved in regulating motility: colonization of Bacteroides thetaiotaomicron resulted in an increase in mRNA encoding the L-glutamate transporter, glutamate decarboxylase (which converts L-glutamate to gamma-aminobutyric acid), synaptobrevin binding protein (which is involved in the release of neurotransmitters), and intestinal g-actin. These findings suggest that the microbiota may directly influence the intestinal nervous system and therefore motility. ${ }^{43}$ In addition, SCFA produced by intestinal microbiota was observed to induce a phase of muscle contraction dependent on GPR41 (G proteincoupled receptor 41) level, with the highest affinity being observed for propionate, followed by butyrate and acetate. GPR41, also known as free fatty acid receptor 3 (FFAR3), is a free fatty acid receptor coupled to a $G$ protein, encoded by the FFAR3 gene. GPR41 has an affinity to both ethanoic and propionic acid, and a lower affinity for butyric acid. To a small extent, it also recognizes caproic and valeric acid. ${ }^{25}$

\section{Neuroendocrine factors}

The microbiota of the digestive tract affects peristalsis by stimulating the sympathetic nervous system and relaxing the smooth muscle of the intestine. Microorganisms stimulate cholinergic pathways directly through their ability to synthesize neurotransmitters. It has been found that Lactococcus, Streptococcus, Escherichia, and Candida effectively increase the concentration of serotonins, Lactobacillus and Bifidobacterium increase gamma-aminobutyric acid, and Bacillus spp., Escherichia spp. and Saccharomyces spp. increase norepinephrine. The gastrointestinal microbiota can also stimulate cholinergic pathways indirectly through the synthesis of metabolites such as SCFAs (e.g., butyrate), thus stimulating the release of serotonin. It has also been shown that Faecalibacterium, Roseburia and Coprococcus produce butyrate, and thus increase serotonin levels. ${ }^{2,39}$

\section{Role in bile acid metabolism}

The intestinal microbiota can also affect intestinal motility by modulating the composition and size of the bile acid pool. The microorganisms colonizing the colon participate in the deconjugation and dehydroxylation of primary bile acids (cholic and chenodeoxycholic acid) which are absorbed in the ileum. Secondary bile acids, such as deoxycholic and lithocholic acid, are formed. The conjugation of primary bile acids in the large intestine is facilitated by bacterial $7 \alpha$-dehydroxylase, the activity of which has been observed in Clostridium leptum, Clostridium bifermentans, Clostridium sordellii, Eubacterium spp., Escherichia coli, and Bacteroides spp.

Lithocholic acid, the most potent TGR5 membrane receptor activator conjugated to $G$ protein, is also involved in the regulation of metabolism. Studies on mice overexpressing TGR5 identified a 2.2 -fold reduction in colonic transit time and a 2.6-fold increase in the number of bowel movements compared to normal mice.

It is also possible that intestinal motility is affected by cholic acid, which is found to be present at higher levels in obese people. Obesity also influences the specific composition of the intestinal microbiota; e.g., obese people tend to demonstrate a greater abundance of Firmicutes compared to Bacteroidetes, which is associated with a faster peristalsis. $^{39}$

\section{The influence of particular bacterial strains on peristalsis and the prevention of constipation}

A great deal of research has been conducted to determine the effect of individual bacterial strains on intestinal motility and the occurrence of constipation, and the results are varied and often contradictory. These differences may result from the fact that children with constipation constitute a highly heterogeneous phenotypical group, and the fact that previous studies use a wide range of diagnostic criteria, methods of patient classification, patient diets, and research methods used to identify the microbiome. Unfortunately, research into microbiota composition has long been limited by the need to use traditional bacterial culture. However, the recent development of $16 S$ rRNA gene pyrosequencing and specific gene primers, and the ability to assess the DNA sequence of each taxon in the intestinal microbiome, has provided a clearer view of the molecular basis of constipation.

Changes in intestinal barrier permeability and systemic resistance observed in adults with constipation have been associated with the presence of a reduced number of Bifidobacteria, Lactobacillus and Prevotella. ${ }^{40}$

A study of the fecal microbiota in 50 adult female patients ( 25 with constipation and 25 without) by $16 S r R N A$ sequencing found that the fecal microbiota profile was 
associated with colonic transit time: the presence of Firmicutes bacteria (Faecalibacterium, Lactococcus and Roseburia) was correlated with faster digestive passage. ${ }^{39}$ Another study found significantly reduced numbers of Bacteroides fragilis, Bacteroides ovatus, Bifidobacterium longum, and Alistipes finegoldi, as well as an increased number of Parabacteroides species, in 76 children aged 4-18 years with functional constipation. ${ }^{15}$ Another study of children aged 6-36 months found a lower number of Lactobacillus bacteria per milligram of feces in a group of 39 children with constipation compared to a group of 40 children without constipation; however, the number of Bifidobacterium did not differ between the 2 groups. ${ }^{6}$

Another study based on $16 S$ rRNA gene pyrosequencing compared the microbiological composition of feces of obese children and the occurrence of constipation. It was found that the number of Bacteroides was significantly reduced in children with constipation; this was mainly accounted for by a reduced number of Prevotella and an increased number of Firmicutes in the children without constipation. The children with obesity did not demonstrate any changes in the Lactobacillus or Bifidobacteria fractions. ${ }^{2}$ It is worth emphasizing that obesity is characterized by a particular microbiota composition of the digestive tract, and that it is possible that such changes may explain the greater likelihood of functional constipation in obese children. ${ }^{2}$

According to Vandeputte et al., stool consistency is strongly associated with the composition and richness of the intestinal microbiota. ${ }^{44}$ Stool consistency, assessed using the Bristol stool scale (where a low score indicates hard stool and slow passage through the colon, and a high score indicates loose consistency and a short passage through the colon), was negatively correlated with species richness and positively related to the Bacteroides : Firmicutes ratio. ${ }^{44}$

Children with functional constipation (mean age: 9.5 years) had a significantly higher level of Clostridium and Bifidobacterium species than healthy subjects (mean age: 7.9 years) ${ }^{46}$ In this study, it was also proved that C. sporogenes, C. paraputrificum, C. fallax, and C. innocuum were dominant among the Clostridium species. ${ }^{46}$

\section{Reports of gut microbiota in functional constipation according to age}

Reports of gut microbiota in functional constipation in relation to age are inconsistent and there is currently no consensus as to which gut microbiota are involved, mainly because the gut microbiota naturally changes according to age. ${ }^{45}$ There are some reports which analyzed gut microbiota in children and in adults with functional constipation. Zhu et al. ${ }^{2}$ used $16 S$ rRNA gene pyrosequencing to demonstrate that children with functional constipation (mean age: 11.8 years) had a significantly lower level of Bacteroidetes, in particular Prevotella, and an increased level of several species of Firmicutes, including Lactobacillus. They also demonstrated that the levels of Lactobacillus and Bifidobacteria species were not reduced. Khalif et al. analyzed gut microbiota in adults with functional constipation and showed a reduced level of Bifidobacterium, Lactobacillus, Bacteroides and Clostridium species, and an increased level of Enterobacteriaceae, such as Escherichia coli, as well as Staphylococcus aureus and fungi. ${ }^{40}$ In another study, it was demonstrated that adult patients with functional constipation had a significantly lower level of Bifidobacterium and Bacteroides. ${ }^{47}$ Parthasarathy et al. demonstrated that although no difference was present in the amount of bacterial species at the genus level between functional constipation adults and healthy control groups, patients with constipation, including those with IBS, had increased levels of Bacteroidetes in their mucosa. ${ }^{39}$

The results of the studies are varied and do not allow the determination of patterns of gut microbiota in children as opposed to adults. More studies are required to reach any conclusions.

\section{The influence of diet on the composition of the gut microbiota and the occurrence of constipation}

Eating habits play an important role in the etiology of constipation. Diet affects the occurrence of constipation directly, by directly altering stool weight and water content, therefore potentially slowing passage through the intestines and preventing excretion, as well as indirectly, by modulating the composition of the intestinal microbiota.

Various elements of the diet (discussed below) can affect the occurrence of functional constipation.

\section{Effect of fiber consumption}

Consumption of low levels of fiber-rich products (watersoluble and water-insoluble fiber) such as vegetables and fruit, can significantly hasten the pathogenesis of functional constipation. Water-insoluble fiber, such as cellulose and lignans that build plant cell walls, absorb water. This causes the stool to expand and soften, making bowel movements easier and more frequent. Soluble fiber includes pectins, mucilages and gums. Fiber cannot be hydrolyzed directly by the human gut: intestinal microbiota, more specifically saccharolytic bacteria such as Bifidobacterium and Lactobacillus spp., are needed to ferment dietary water-soluble fiber to SCFAs and lactic acid, thus reducing intestinal $\mathrm{pH} .{ }^{6}$ Low intestinal $\mathrm{pH}$ stimulates smooth muscle and increases the speed of peristalsis, thus reducing 
intestinal transit time. In addition, low intestinal $\mathrm{pH}$ promotes the growth of beneficial intestinal microbes, especially Bifidobacterium and Lactobacillus spp. Therefore, a diet with the correct water-soluble fiber content facilitates colonization of the intestines by live microorganisms. These properties of soluble fiber are used in the treatment of patients with functional constipation. Children consuming higher amounts of fruit and vegetables tend to have higher numbers of Bifidobacterium in the intestine, and those who do not consume as much are more likely to suffer from constipation. ${ }^{6}$

It has also been shown that higher fiber intake is significantly associated with 4 or more bowel movements per week. In addition, regular consumption of potatoes, legumes, vegetables, and fruit among children has been shown to reduce the incidence of infrequent bowel movements, i.e., less than 3 bowel movements per week. ${ }^{48}$ De Filippo et al. report that children with a high fiber content in their diet tend to have microbiomes richer in Bifidobacteria than children on lower fiber diets. ${ }^{49}$ Similar results were obtained by Bernal et al. ${ }^{50}$ It has been proposed that children on a low-fiber diet are more likely to suffer from constipation because such a diet hinders colonization of the intestines by beneficial microorganisms. ${ }^{6}$

Dietary advice currently recommends consuming an optimal amount of fiber and fluids, and advises against excessive fibre. ${ }^{51}$ A meta-analysis conducted in 2017 found insufficient evidence for the inclusion of fiber supplementation in the treatment of constipation in children and adolescents. ${ }^{52}$

\section{Impact of dairy products and sweets}

Research has found that high consumption of simple sugars, fatty acids and proteins in children aged $3-18$ years is associated with low Lactobacillus content in feces and a frequent occurrence of constipation. Cow's milk protein intake has been positively associated with intestinal constipation in children aged 3-12 years. ${ }^{53}$ Kocaay et al. also note a positive relationship between the occurrence of constipation and cow's milk consumption exceeding $250 \mathrm{~mL}$ per day. ${ }^{54}$ The mechanism behind this correlation has not been fully explained. Protein intake is thought to modulate the intestinal microbiota and it has been proposed that the greater occurrence of constipation observed in such children may be associated with the fact that children who consume larger amounts of cow's milk and sweets tend to consume less fiber-rich products. ${ }^{54}$

The data on the relationship between cow's milk protein allergy (CMPA) and the development of functional constipation are inconsistent. It has been shown that children with CMPA are significantly more likely to show symptoms of gastrointestinal disorders meeting the Rome IV criteria (45\%) compared to controls without CMPA (15\%). In addition, conventional treatment of constipation combined with elimination of cow's milk protein was found to be more effective than therapy without an elimination diet. ${ }^{55}$ Iacono et al. reported that $68 \%$ of children with chronic constipation demonstrated improvement after eliminating cow's milk from the diet; however, all children developed constipation after re-inclusion of milk into the diet. ${ }^{56}$ Daher et al. also reported a relationship between CMPA and constipation. ${ }^{57}$ However, no such relationship was observed in other studies: Simeone et al. found that the incidence of atopy among children with functional constipation was similar to that in the general population, and that constipation was not improved by a four-week elimination of cow's milk protein from the diet. ${ }^{58}$

\section{Impact of fat intake}

Vakili at al. demonstrated that a high dietary saturated fat intake is associated with a significant increase in the prevalence of constipation. ${ }^{59}$ The authors showed that after a high-fat meal, healthy people demonstrate a lengthening phase of the peristaltic waves of the intestine. In studies on rodents, a high-fat diet was associated with lower availability of serotonin in the large intestine and dysbiosis, which resulted in delayed colon motility. ${ }^{48}$ A high-fat diet delayed intestinal transit, which was associated with increased apoptosis and loss of colonic myenteric neurons. ${ }^{60,61}$ Saturated fatty acids such as palmitate have also been shown to cause apoptosis of enteric neuronal cells, ${ }^{60}$ while unsaturated fatty acids such as oleic acid stimulate peristalsis and prevent neuronal damage. ${ }^{61}$ Sayegh et al. demonstrated that intra-intestinal infusion of oleate has been shown to activate myenteric neurons in the duodenum and jejunum, but not the ileum. ${ }^{62}$

\section{Physical activity, functional constipation and the microbiome}

Constipation may be caused by low physical activity. Physical activity is thought to stimulate intestinal peristalsis, thus shortening the duration of food passage through the colon and rectum. ${ }^{63}$ This effect has been attributed to hormonal changes. ${ }^{64}$ Physical activity affects the level of endogenous sex hormones, which regulate the passage of food through the colon. However, fluctuations of sex hormone levels do not seem to significantly affect colonic motility in children before puberty. Reduced progesterone levels in postmenopausal women has been shown to shorten the time for food to pass through the digestive tract. ${ }^{65}$ Transient variations in blood supply to the gastrointestinal tract and changes in the balance between sympathetic and parasympathetic innervation have also been shown to affect digestive transit. ${ }^{70}$

Driessen et al. report that increased physical activity (as measured by an accelerometer) was associated with a reduced risk of functional constipation in Dutch preschool children. ${ }^{66}$ Similarly, high levels of physical activity 
have been found to be significantly associated with a lower rick of constipation in a group of 5000 Japanese preschoolers, ${ }^{67}$ and in 234 Romanian children aged $4-18$ years. ${ }^{68}$ In addition, an analysis of 14,626 Taiwanese teenagers found that encouraging greater physical activity can be helpful in preventing constipation, ${ }^{69}$ and insufficient physical activity, i.e., less than $1 \mathrm{~h}$ of activity per day, and an excessively sedentary lifestyle, i.e., over $4 \mathrm{~h}$ per day, were associated with constipation in a group of 33,692 Hong Kong students. ${ }^{3}$

Currently, a study involving 338 Japanese adults examining whether a decrease in physical activity may contribute to the development of constipation by disturbing the gastrointestinal microbiota is ongoing. The available results indicate a statistically significant difference in the mean frequency of defecation (i.e., less than once per day or less than once per week) between more and less physically active people, with activity measured throughout the day using an accelerometer: intestinal peristalsis was about $10 \%$ faster in older people who completed 7000 steps per day or spent 15 min per day engaged in activity $>3$ MET (metabolic equivalents) compared with those who completed $<7000$ steps/day or engaged in $<15 \mathrm{~min} /$ day activity $>3$ MET. However, no relationship was found between physical activity and the composition of the intestinal microbiota. The authors conclude that moderate daily physical activity reduces the risk of infrequent bowel movements mainly through mechanical stimulation of intestinal motility, without changing the composition of the microbiota. ${ }^{70}$

It has also been found that the structure and abundance of butyrate-producing microorganisms in the colon did not change significantly after cessation of physical activity. This may suggest that the intestinal microbiota is resistant to short-term changes in host level of exercise or hypoxia. Nevertheless, defecation difficulties were observed shortly after cessation of physical activity, most probably due to slowed intestinal motility. ${ }^{71}$

\section{Conclusions}

The wide prevalence and the growing problem of constipation suggests that existing therapeutic methods require improvement; therefore, new therapeutic possibilities are constantly being sought. The exiting literature indicates that the structure of the intestinal microbiota may be associated with the occurrence of functional constipation, hence new therapeutic solutions are being sought in the modulation of microbiota. Further research is needed to clarify the composition of the intestinal microbiota in patients with functional constipation and to determine its importance in the pathogenesis of the disease.

\section{ORCID iDs}

Monika Kwiatkowska (D) https://orcid.org/0000-0002-7057-3248 Aneta Krogulska (D) https://orcid.org/0000-0002-5280-1876

\section{References}

1. Biggs WS, Dery WH. Evaluation and treatment of constipation in infants and children. Am Fam Physician. 2006;73(3):469-477. PMID:16477894

2. Zhu L, Liu W, Alkhouri R, et al. Structural changes in the gut microbiome of constipated patients. Physiol Genomics. 2014;46(18):679-686. doi:10.1152/physiolgenomics.00082.2014

3. Huang R, Hu J. Positive effect of probiotics on constipation in children: A systematic review and meta-analysis of six randomized controlled trials. Front Cell Infect Microbiol. 2017;7:153. doi:10.3389/fcimb. 2017.00153

4. Pawłowska K, Umławska W, Iwańczak B. A link between nutritional and growth states in pediatric patients with functional gastrointestinal disorders. J Pediatr. 2018;199:171-177. doi:10.1016/j.jpeds. 2018.02.069

5. Lewis ML, Palsson OS, Whitehead WE, van Tilburg MAL. Prevalence of functional gastrointestinal disorders in children and adolescents. J Pediatr. 2016;177:39-43.e3. doi:10.1016/j.jpeds.2016.04.008

6. Gomes de Moraes J, Farias de Almeida Motta ME, Ferraz de Sa Beltrão M, Salviano TL, Alves Pontes da Silva G. Fecal microbiota and diet of children with chronic constipation. Int J Pediatr. 2016;2016:6787269. doi:10. $1155 / 2016 / 6787269$

7. Rajindrajith S, Devanarayana NM, Crispus Perera BJ, Benninga MA. Childhood constipation as an emerging public health problem. World J Gastroenterol. 2016;22(30):6864-6875. doi:10.3748/wjg.v22.i30.6864

8. Huang L, Zhu Q, Qu X, Qin H. Microbial treatment in chronic constipation. Sci China Life Sci. 2018;61(7):744-752. doi:10.1007/s11427-0179220-7

9. Bongers MEJ, van Wijk MP, Reitsma JB, Benninga MA. Long-term prognosis for childhood constipation: Clinical outcomes in adulthood. Pediatrics. 2010;126(1):e156-e162. doi:10.1542/peds.2009-1009

10. Dehghani SM, Basiratnia M, Matin M, Hamidpour L, Haghighat $M$, Imanieh $\mathrm{MH}$. Urinary tract infection and enuresis in children with chronic functional constipation. Iran J Kidney Dis. 2013;7(5):363-366. PMID:24072148

11. Steutel NF, Zeevenhooven J, Scarpato E, et al. Prevalence of functional gastrointestinal disorders in European infants and toddlers. J Pediatr. 2020;221:107-114. doi:10.1016/j.jpeds.2020.02.076

12. Fontana $M$, Bianchi $C$, Cataldo $F$, et al. Bowel frequency in healthy children. Acta Paediatr Scand. 1989;78(5):682-684. doi:10.1111/j. 1651-2227.1989.tb11126.x

13. Benninga MA, Nurko S, Faure C, Hyman PE, St. James Roberts I, Schechter NL. Childhood functional gastrointestinal disorders: Neonate/toddler. Gastroenterology. 2016;150(6):1443-1455.e2. doi:10.1053/ j.gastro.2016.02.016

14. Hyams JS, Di Lorenzo C, Saps M, Shulman RJ, Staiano A, van Tilburg M. Childhood functional gastrointestinal disorders: Child/adolescent. Gastroenterology. 2016;150(6):1456-1468.e2. doi:10.1053/j.gastro. 2016.02.015

15. de Meij TGJ, de Groot EFJ, Eck A, et al. Characterization of microbiota in children with chronic functional constipation. PLoS One. 2016;11(10):e0164731. doi:10.1371/journal.pone.0164731

16. van Mill MJ, Koppen IJN, Benninga MA. Controversies in the management of functional constipation in children. Curr Gastroenterol Rep. 2019;21(6):23. doi:10.1007/s11894-019-0690-9

17. Amendola S, De Angelis P, Dall'Oglio L, di Abriola GF, Di Lorenzo M. Combined approach to functional constipation in children. J Pediatr Surg. 2003;38(5):819-823. doi:10.1016/jpsu.2003.50174

18. Ohkusa T, Koido S, Nishikawa Y, Sato N. Gut microbiota and chronic constipation: A review and update. Front Med. 2019;6:19. doi:10.3389/ fmed.2019.00019

19. Rao SSC, Patcharatrakul T. Diagnosis and treatment of dyssynergic defecation. J Neurogastroenterol Motil. 2016;22(3):423-435. doi:10. 5056/jnm16060

20. Whitehead WE, Wald A, Diamant NE, Enck P, Pemberton JH, Rao SSC. Functional disorders of the anus and rectum. Gut. 1999;45(Suppl 2): ii55-ii59. doi:10.1136/gut.45.2008.ii55

21. Rajindrajith S, Devanarayana NM. Constipation in children: Novel insight into epidemiology, pathophysiology and management. J Neurogastroenterol Motil. 2011;17(1):35-47. doi:10.5056/jnm.2011.17.1.35

22. Zar-Kessler C, Kuo B, Cole E, Benedix A, Belkind-Gerson J. Benefit of pelvic floor physical therapy in pediatric patients with dyssynergic defecation constipation. Dig Dis. 2019;37(6):478-485. doi:10.1159/ 000500121 
23. Nurko S, Scott SM. Coexistence of constipation and incontinence in children and adults. Best Pract Res Clin Gastroenterol. 2011;25(1): 29-41. doi:10.1016/j.bpg.2010.12.002

24. Nullens S, Nelsen T, Camilleri M, et al. Regional colon transit in patients with dys-synergic defaecation or slow transit in patients with constipation. Gut. 2012;61(8):1132-1139. doi:10.1136/gutjnl-2011-301181

25. Morais MB, Vítolo MR, Aguirre ANC, Fagundes-Neto U. Measurement of low dietary fiber intake as a risk factor for chronic constipation in children. J Pediatr Gastroenterol Nutr. 1999;29(2):132-135. doi:10. 1097/00005176-199908000-00007

26. Yamada M, Sekine M, Tatsuse T. Psychological stress, family environment, and constipation in Japanese children: The Toyama Birth Cohort Study. J Epidemiol. 2019;29(6):220-226. doi:10.2188/jea.JE 20180016

27. vd Baan-Slootweg $\mathrm{OH}$, Liem O, Bekkali $\mathrm{N}$, et al. Constipation and colonic transit times in children with morbid obesity. J Pediatr Gastroenterol Nutr. 2011;52(4):442-445. doi:10.1097/MPG.0b013e3181ef8e3c

28. Koppen IJN, Velasco-Benítez CA, Benninga MA, Di Lorenzo C, Saps M. Is there an association between functional constipation and excessive bodyweight in children? J Pediatr. 2016;171:178-182.e1. doi:10. 1016/j.jpeds.2015.12.033

29. Tam YH, Li AM, So HK, et al. Socioenvironmental factors associated with constipation in Hong Kong children and Rome III Criteria. J Pediatr Gastroenterol Nutr. 2012;55(1):56-61. doi:10.1097/MPG.0b0 13e31824741ce

30. Ostwani W, Dolan J, Elitsur Y. Familial clustering of habitual constipation: A prospective study in children from West Virginia. J Pediatr Gastroenterol Nutr. 2010;50(3):287-289. doi:10.1097/MPG.0b013 e3181a0a595

31. Peeters B, Benninga MA, Hennekam RC. Childhood constipation; An overview of genetic studies and associated syndromes. Best Pract Res Clin Gastroenterol. 2011;25(1):73-88. doi:10.1016/j.bpg.2010.12.005

32. Simrén $M$, Barbara $G$, Flint $H J$, et al. Intestinal microbiota in functional bowel disorders: A Rome Foundation report. Gut. 2013;62(1):159-176. doi:10.1136/gutjnl-2012-302167

33. Mezzasalma V, Manfrini E, Ferri E, et al. A randomized, double-blind, placebo-controlled trial: The efficacy of multispecies probiotic supplementation in alleviating symptoms of irritable bowel syndrome associated with constipation. Biomed Res Int. 2016;2016:4740907. doi:10.1155/2016/4740907

34. Ramakrishna BS. Role of the gut microbiota in human nutrition and metabolism: Role of the gut microbiota. J Gastroenterol Hepatol. 2013; 28:9-17. doi:10.1111/jgh.12294

35. de Oliveira GLV, Leite AZ, Higuchi BS, Gonzaga MI, Mariano VS. Intestinal dysbiosis and probiotic applications in autoimmune diseases. Immunology. 2017;152(1):1-12. doi:10.1111/imm.12765

36. Asano $Y$, Hiramoto $T$, Nishino R, et al. Critical role of gut microbiota in the production of biologically active, free catecholamines in the gut lumen of mice. Am J Physiol Gastrointest Liver Physiol. 2012; 303(11):G1288-G1295. doi:10.1152/ajpgi.00341.2012

37. Rousseaux C, Thuru X, Gelot A, et al. Lactobacillus acidophilus modulates intestinal pain and induces opioid and cannabinoid receptors. Nat Med. 2007;13(1):35-37. doi:10.1038/nm1521

38. Pothmann A, Illing T, Wiegand C, Hartmann AA, Elsner P. The microbiome and atopic dermatitis: A review. Am J Clin Dermatol. 2019;20(6): 749-761. doi:10.1007/s40257-019-00467-1

39. Parthasarathy G, Chen J, Chen X, et al. Relationship between microbiota of the colonic mucosa vs feces and symptoms, colonic transit, and methane production in female patients with chronic constipation. Gastroenterology. 2016;150(2):367-379.e1. doi:10.1053/j.gastro.2015.10.005

40. Khalif I, Quigley E, Konovitch E, Maximova I. Alterations in the colonic flora and intestinal permeability and evidence of immune activation in chronic constipation. Dig Liver Dis. 2005;37(11):838-849. doi:10. 1016/j.dld.2005.06.008

41. Tang WHW, Kitai T, Hazen SL. Gut microbiota in cardiovascular health and disease. Circ Res. 2017;120(7):1183-1196. doi:10.1161/CIRCRESAHA. 117.309715

42. Ojetti V, Petruzziello C, Migneco A, Gnarra M, Gasbarrini A, Franceschi F. Effect of Lactobacillus reuteri (DSM 17938) on methane production in patients affected by functional constipation: A retrospective study. Eur Rev Med Pharmacol Sci. 2017;21(7):1702-1708. PMID: 28429333
43. Hooper LV. Molecular analysis of commensal host-microbial relationships in the intestine. Science. 2001;291(5505):881-884. doi:10.1126/ science.291.5505.881

44. Vandeputte D, Falony G, Vieira-Silva S, Tito RY, Joossens M, Raes J. Stool consistency is strongly associated with gut microbiota richness and composition, enterotypes and bacterial growth rates. Gut. 2016;65(1):57-62. doi:10.1136/gutjnl-2015-309618

45. Yatsunenko T, Rey FE, Manary MJ, et al. Human gut microbiome viewed across age and geography. Nature. 2012;486(7402):222-227. doi:10.1038/nature11053

46. Zoppi G, Cinquetti M, Luciano A, Benini A, Muner A, Minelli EB. The intestinal ecosystem in chronic functional constipation. Acta Paediatr. 2007;87(8):836-841. doi:10.1111/j.1651-2227.1998.tb01547.x

47. Kim SE, Choi SC, Park KS, et al. Change of fecal flora and effectiveness of the short-term VSL\#3 probiotic treatment in patients with functional constipation. J Neurogastroenterol Motil. 2015;21(1):111-120. doi:10.5056/jnm14048

48. Fujitani A, Sogo T, Inui A, Kawakubo K. Prevalence of functional constipation and relationship with dietary habits in 3- to 8-year-old children in Japan. Gastroenterol Res Pract. 2018;2018:3108021. doi:10. $1155 / 2018 / 3108021$

49. De Filippo C, Cavalieri D, Di Paola M, et al. Impact of diet in shaping gut microbiota revealed by a comparative study in children from Europe and rural Africa. Proc Nat Acad Sci. 2010;107(33):14691-14696. doi:10.1073/pnas.1005963107

50. Bernal MJ, Periago MJ, Martínez R, et al. Effects of infant cereals with different carbohydrate profiles on colonic function: Randomised and double-blind clinical trial in infants aged between 6 and 12 months. Pilot study. Eur J Pediatr. 2013;172(11):1535-1542. doi:10.1007/s00431013-2079-3

51. Southwell BR. Treatment of childhood constipation: A synthesis of systematic reviews and meta-analyses. Exp Rev Gastroenterol Hepatol. 2020;14(3):163-174. doi:10.1080/17474124.2020.1733974

52. Piccoli de Mello P, Eifer DA, Daniel de Mello E. Use of fibers in childhood constipation treatment: Systematic review with meta-analysis. J Pediatr (Rio J). 2018;94(5):460-470. doi:10.1016/j.jped.2017.10.014

53. Crowley E, Williams L, Roberts T, Dunstan R, Jones P. Does milk cause constipation? A crossover dietary trial. Nutrients. 2013;5(1):253-266. doi:10.3390/nu5010253

54. Kocaay P, Egritas O, Dalgic B. Normal defecation pattern, frequency of constipation and factors related to constipation in Turkish children 0-6 years old. Turk J Gastroenterol. 2011;22(4):369-375. doi:10.4318/ tjg. 2011.0238

55. Feng BW, Fu SM, Zhang QS, et al. Influence of cow's milk protein allergy on the diagnosis of functional gastrointestinal diseases based on the Rome IV standard in infants and young children [in Chinese]. Zhongguo Dang Dai Er Ke Za Zhi. 2018;20(1):56-59. doi:10.7499/j.issn. 1008-8830.2018.01.012

56. Iacono G, Cavataio F, Montalto G, et al. Intolerance of cow's milk and chronic constipation in children. NEng/ JMed. 1998;339(16):1100-1104. doi:10.1056/NEJM199810153391602

57. Daher S, Tahan S, Sole D, et al. Cow's milk protein intolerance and chronic constipation in children. Pediatr Allergy Immunol. 2001;12(6): 339-342. doi:10.1034/j.1399-3038.2001.0o057.x

58. Simeone D, Miele E, Boccia G, Marino A, Troncone R, Staiano A. Prevalence of atopy in children with chronic constipation. Arch Dis Childhood. 2008;93(12):1044-1047. doi:10.1136/adc.2007.133512

59. Taba Taba Vakili S, Nezami BG, Shetty A, Chetty VK, Srinivasan S. Association of high dietary saturated fat intake and uncontrolled diabetes with constipation: Evidence from the National Health and Nutrition Examination Survey. Neurogastroenterol Motil. 2015;27(10): 1389-1397. doi:10.1111/nmo.12630

60. Nezami BG, Mwangi SM, Lee JE, et al. MicroRNA 375 mediates palmitate-induced enteric neuronal damage and high-fat diet-induced delayed intestinal transit in mice. Gastroenterology. 2014;146(2): 473-483.e3. doi:10.1053/j.gastro.2013.10.053

61. Mushref MA, Srinivasan S. Effect of high fat-diet and obesity on gastrointestinal motility. Ann Transl Med. 2013;1(2):14. doi:10.3978/j.issn. 2305-5839.2012.11.01

62. Sayegh Al, Covasa M, Ritter RC. Intestinal infusions of oleate and glucose activate distinct enteric neurons in the rat. Autonom Neurosci. 2004;115(1-2):54-63. doi:10.1016/j.autneu.2004.08.006 
63. De Schryver AM, Keulemans YC, Peters HP, et al. Effects of regular physical activity on defecation pattern in middle-aged patients complaining of chronic constipation. Scand J Gastroenterol. 2005;40(4): 422-429. doi:10.1080/00365520510011641

64. Mugie SM, Benninga MA, Di Lorenzo C. Epidemiology of constipation in children and adults: A systematic review. Best Pract Res Clin Gastroenterol. 2011;25(1):3-18. doi:10.1016/j.bpg.2010.12.010

65. Chan MF, Dowsett M, Folkerd E, et al. Usual physical activity and endogenous sex hormones in postmenopausal women: The European Prospective Investigation into Cancer - Norfolk Population Study. Cancer Epidemiol Biomarkers Prevent. 2007;16(5):900-905. doi:10.1158/ 1055-9965.EPI-06-0745

66. Driessen LM, Jong JCK, Wijtzes A, et al. Preschool physical activity and functional constipation: The Generation R Study.J Pediatr Gastroenterol Nutr. 2013;57(6):768-774. doi:10.1097/MPG.0b013e3182a313fc

67. Asakura K, Masayasu S, Sasaki S. Dietary intake, physical activity, and time management are associated with constipation in preschool children in Japan. Asia Pac J Clin Nutr. 2017;26(1):118-129. doi:10.6133/ apjcn.112015.02
68. Olaru C, Diaconescu S, Trandafir L, et al. Some risk factors of chronic functional constipation identified in a pediatric population sample from Romania. Gastroenterol Res Pract. 2016;2016:3989721. doi:10. 1155/2016/3989721

69. Chien LY, Liou YM, Chang P. Low defaecation frequency in Taiwanese adolescents: Association with dietary intake, physical activity and sedentary behavior. J Paediatr Child Health. 2011;47(6):381-386. doi:10.1111/j.1440-1754.2010.01990.x

70. Aoyagi $Y$, Amamoto $R$, Park $S$, et al. Independent and interactive effects of habitually ingesting fermented milk products containing Lactobacillus casei strain Shirota and of engaging in moderate habitual daily physical activity on the intestinal health of older people. Front Microbiol. 2019;10:1477. doi:10.3389/fmicb.2019.01477

71. Šket R, Treichel N, Debevec T, et al. Hypoxia and inactivity related physiological changes (constipation, inflammation) are not reflected at the level of gut metabolites and butyrate producing microbial community: The PlanHab Study. Front Physiol. 2017;8:250. doi:10.3389/ fphys.2017.00250 